
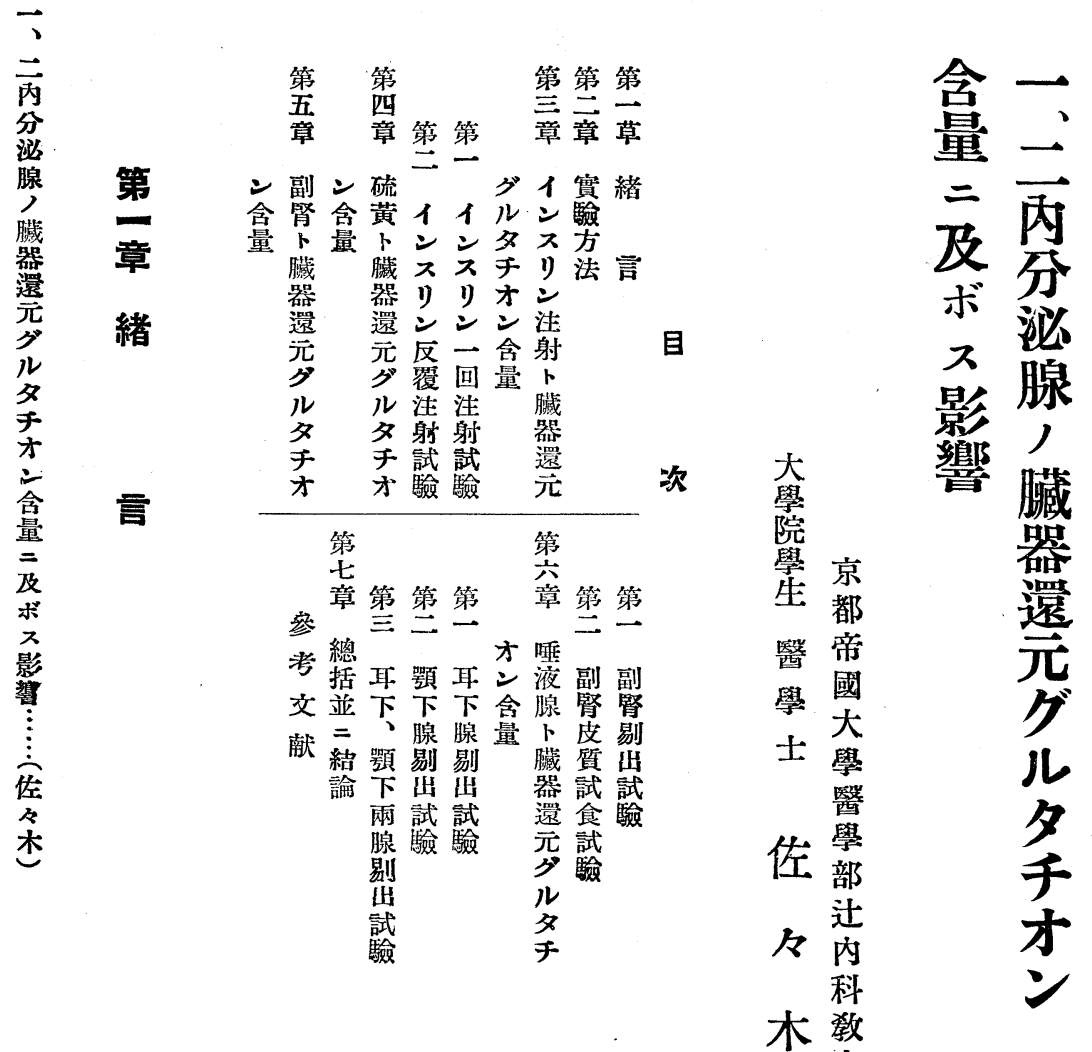

吾

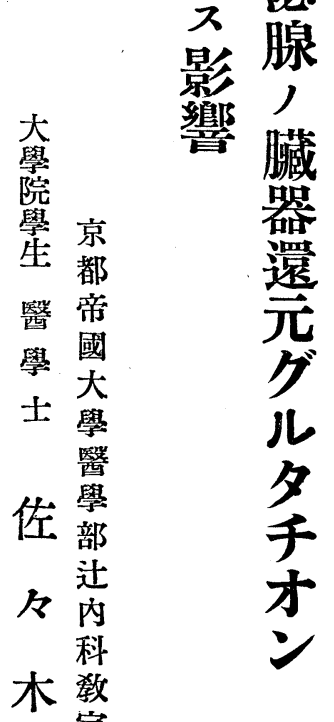

德

太

郎

述 


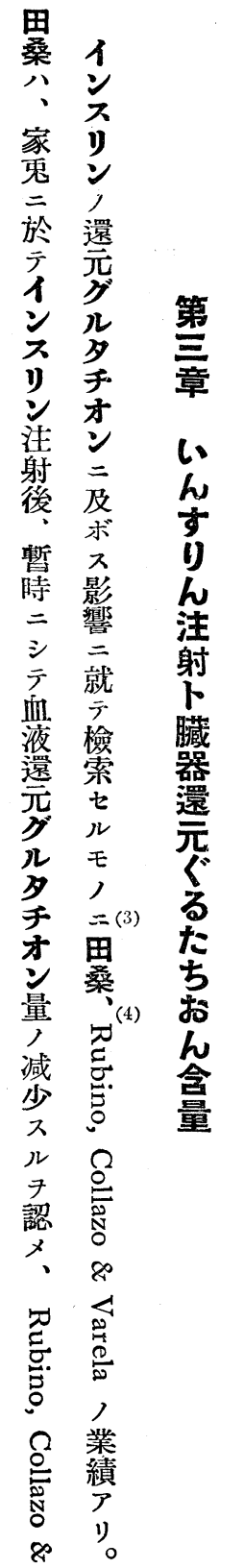

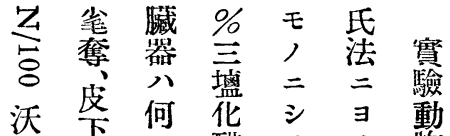

䓍組 モ

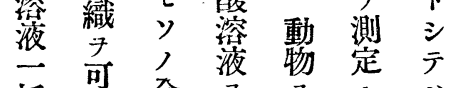

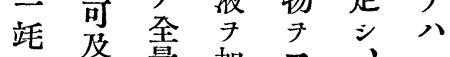

澴的量加工指定

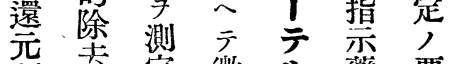

ル セ 定 微 ル 藥 要

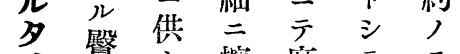

ん乎背 シ 擦麻筑 テ モ

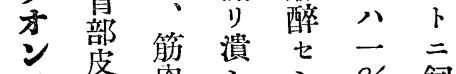

三膚肉 シ シ \% 柃

五 百 大 同頙粉 養

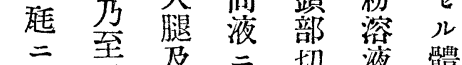

相至 芜

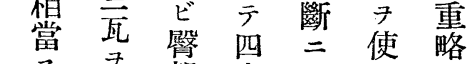

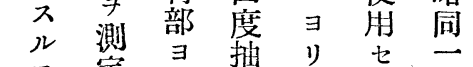

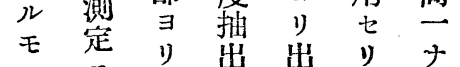

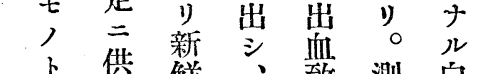

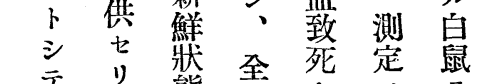

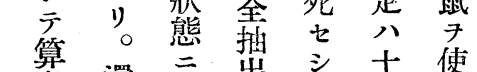

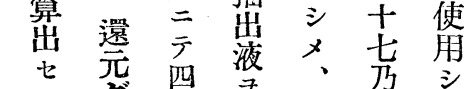

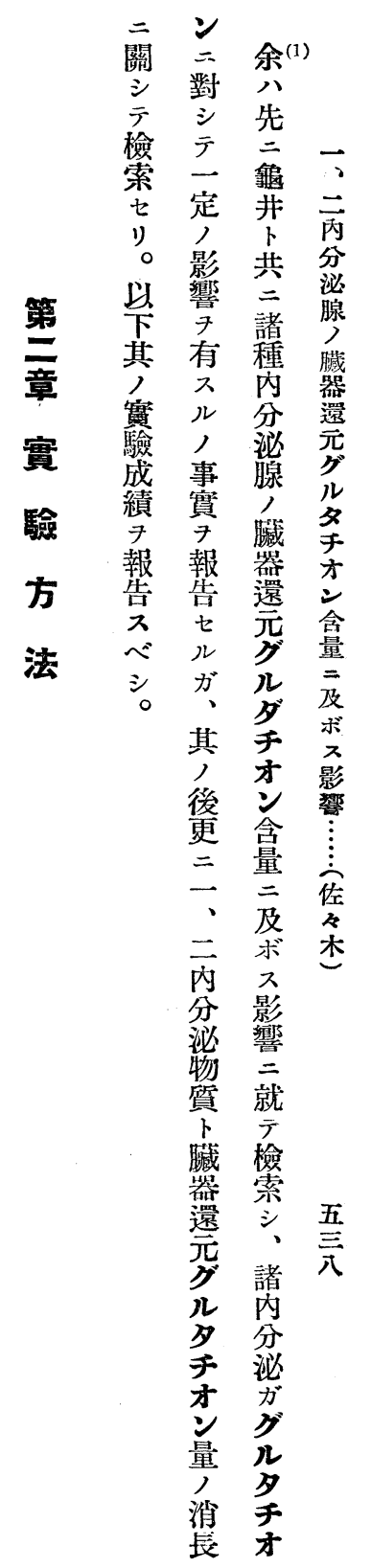



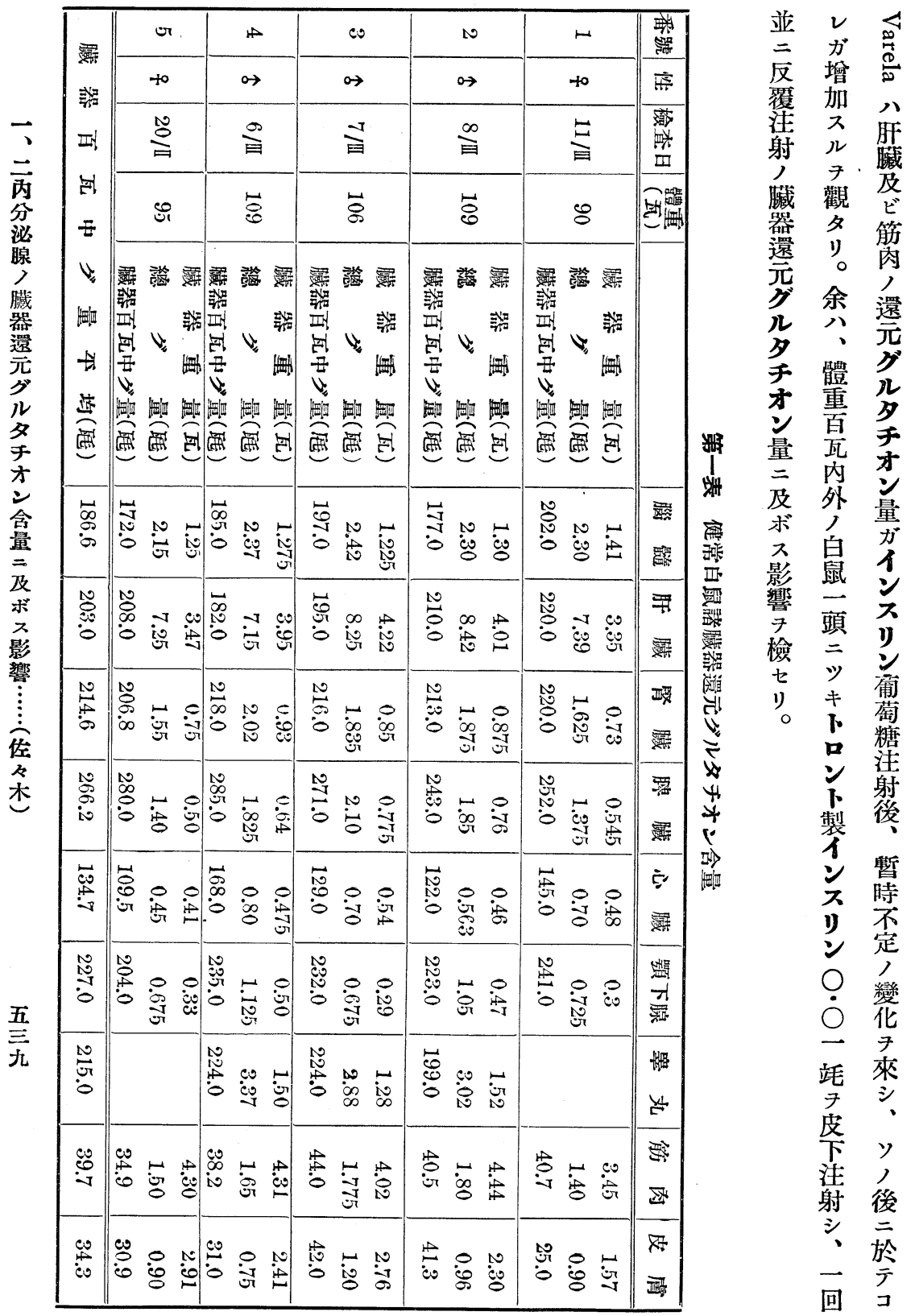


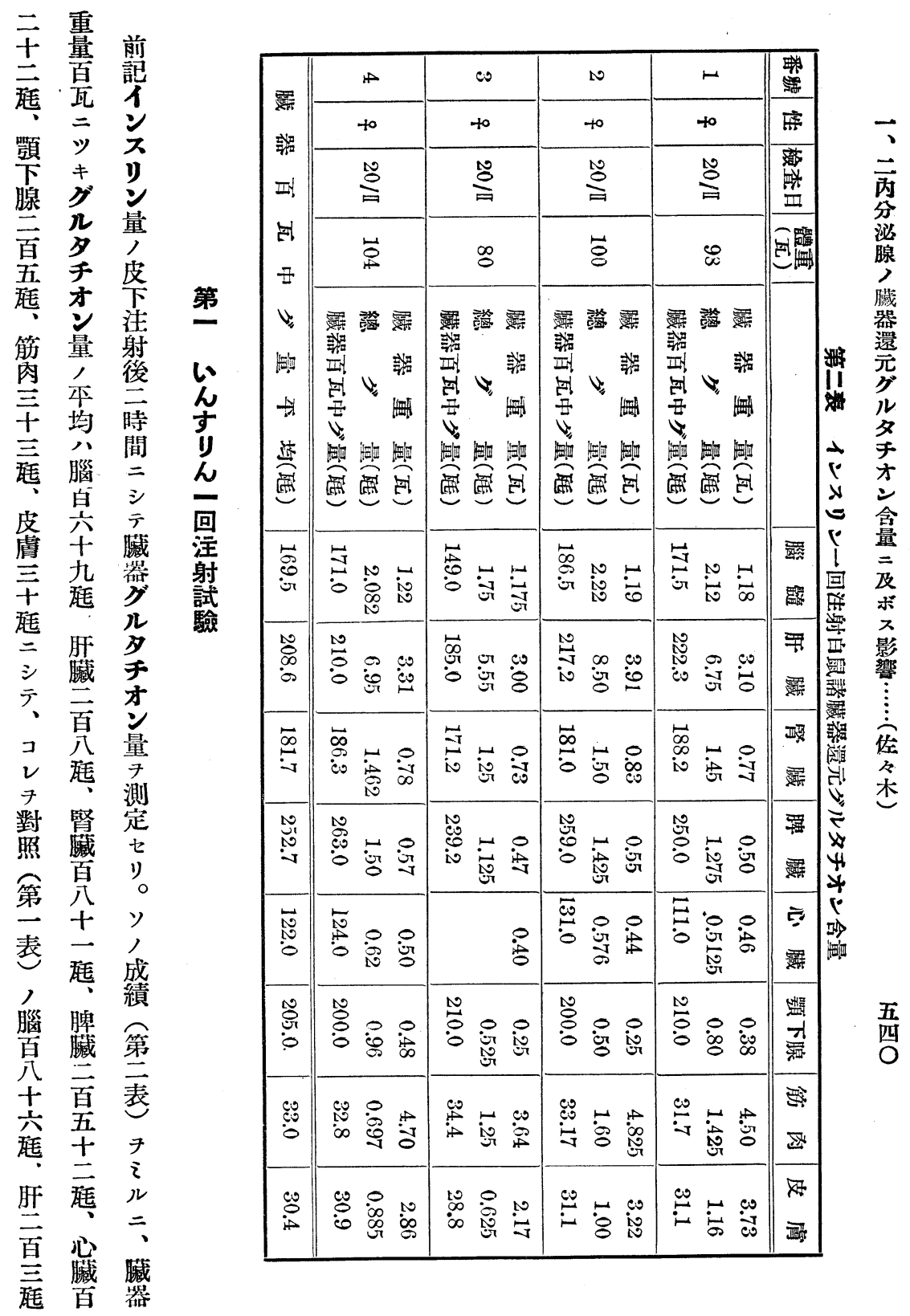




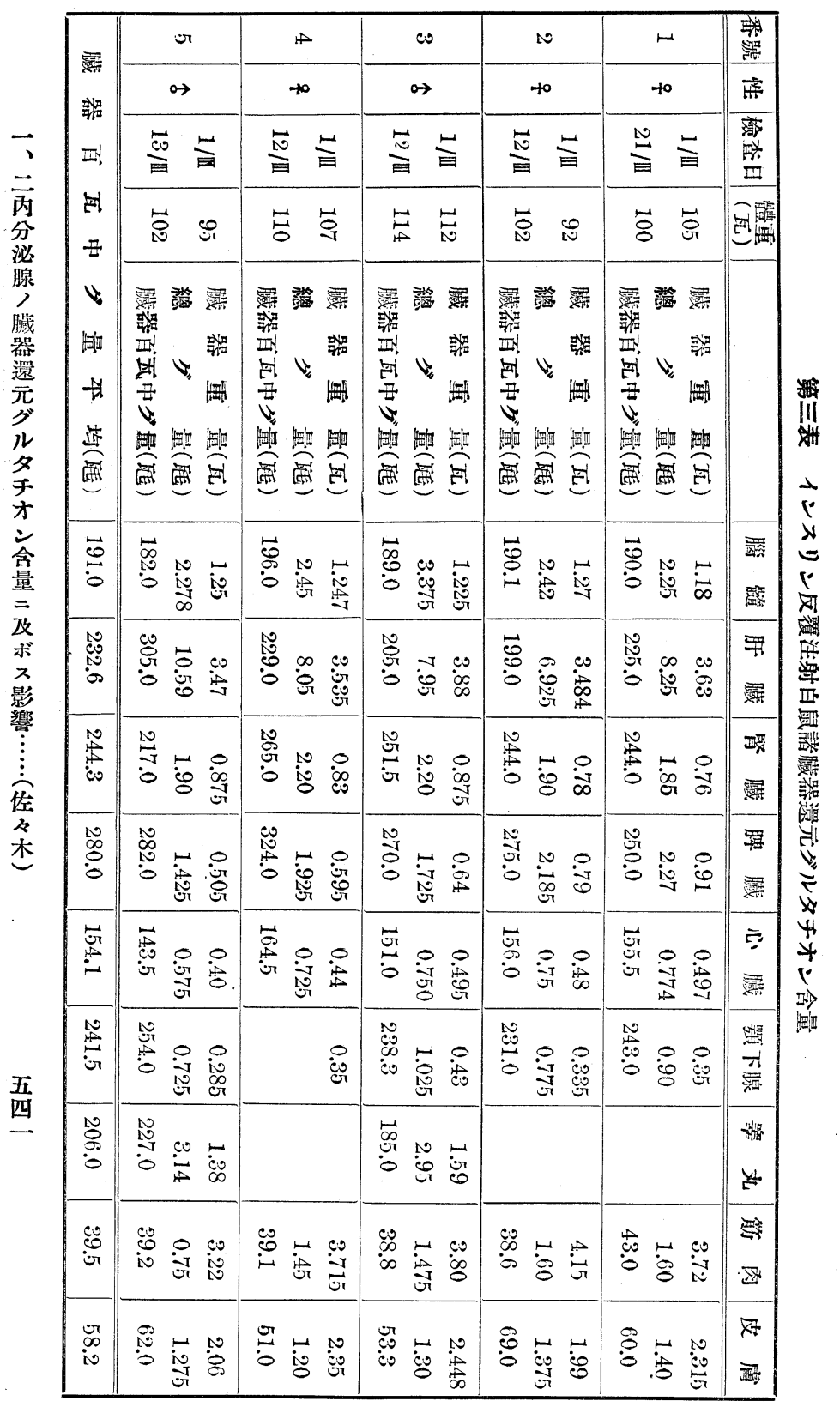

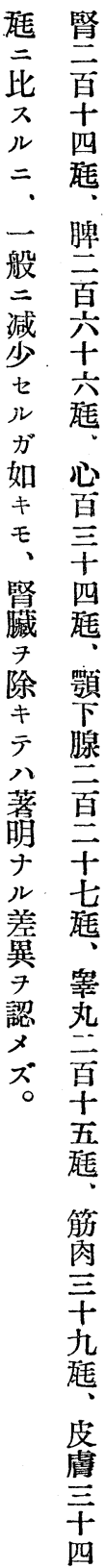




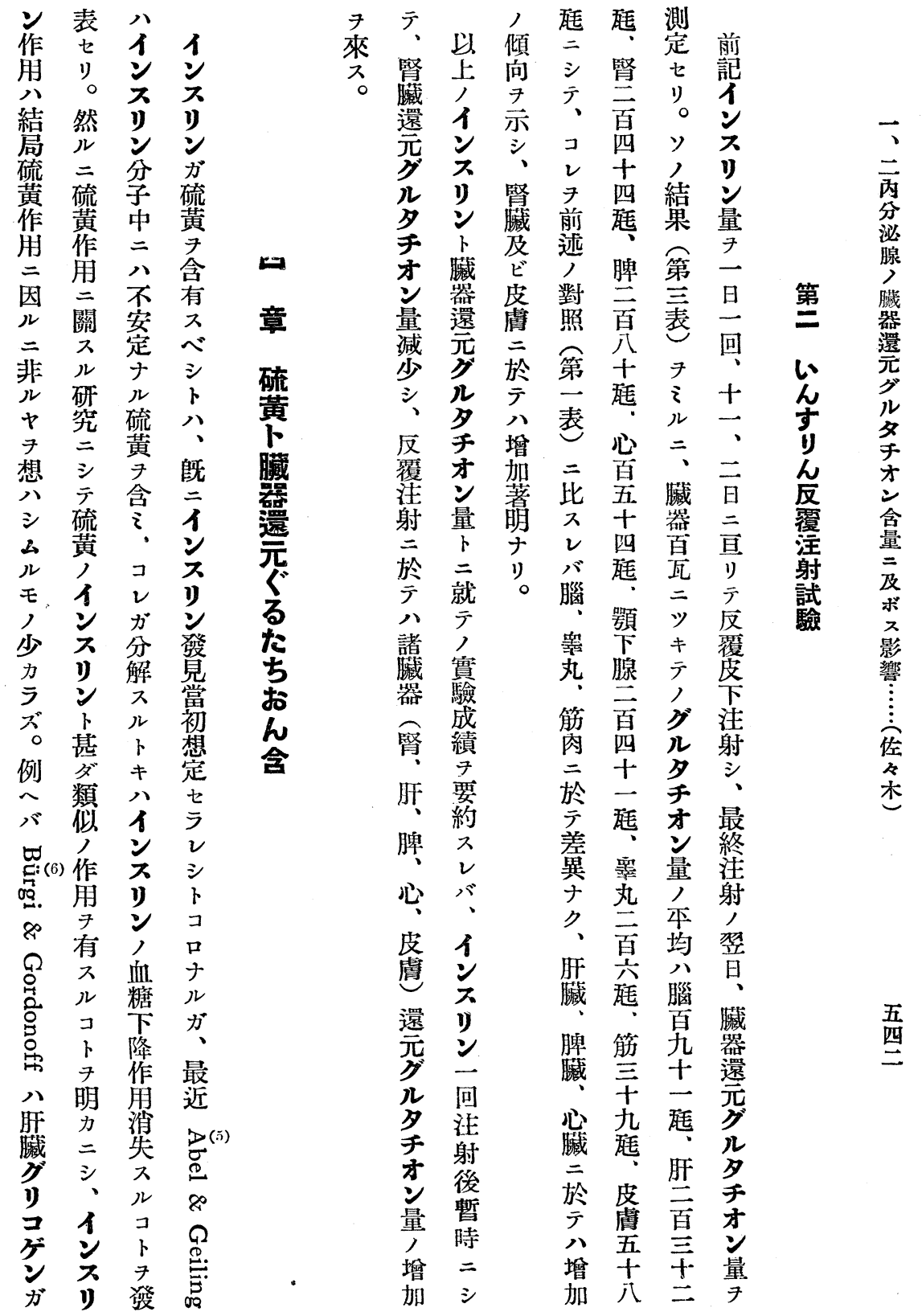



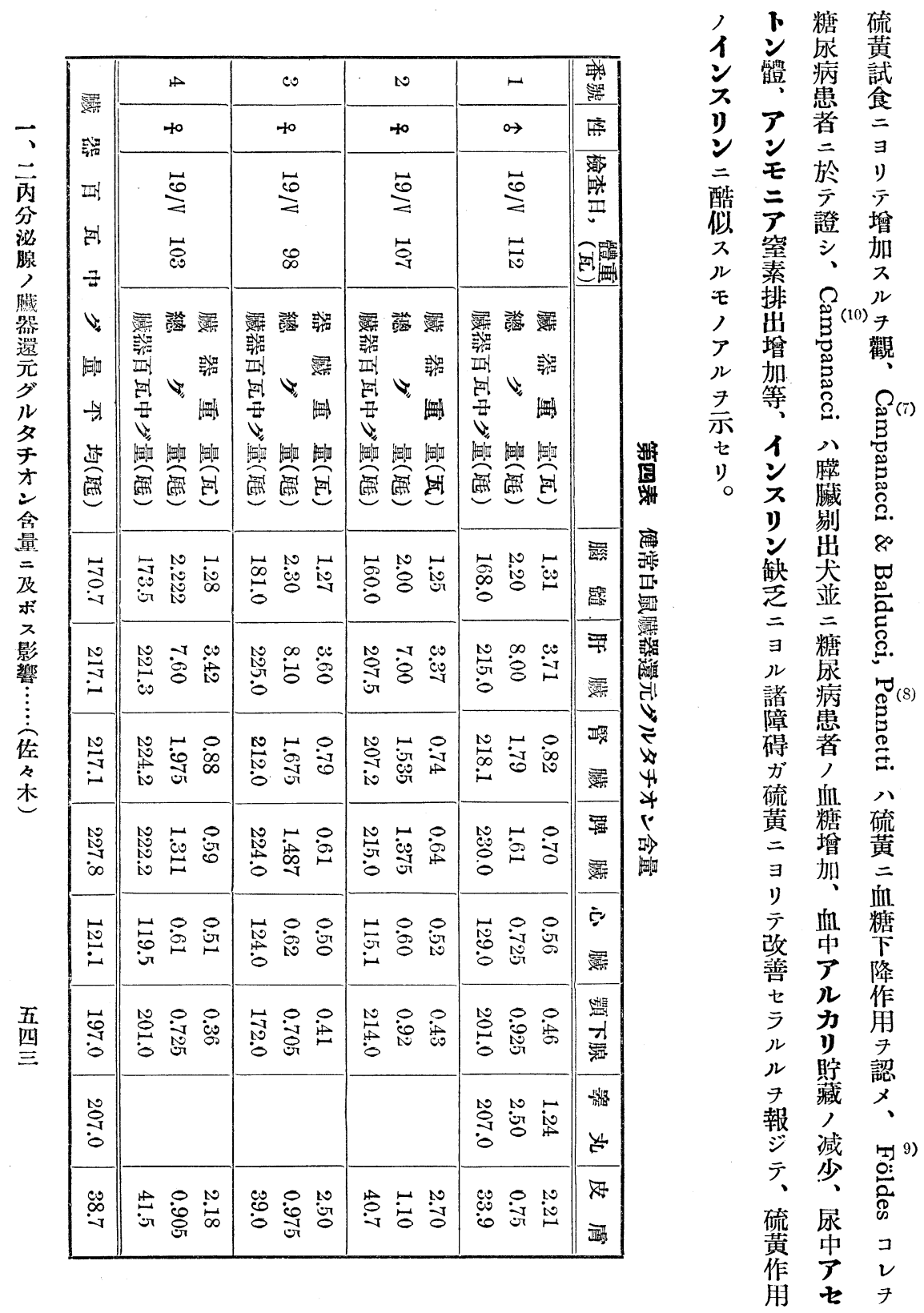


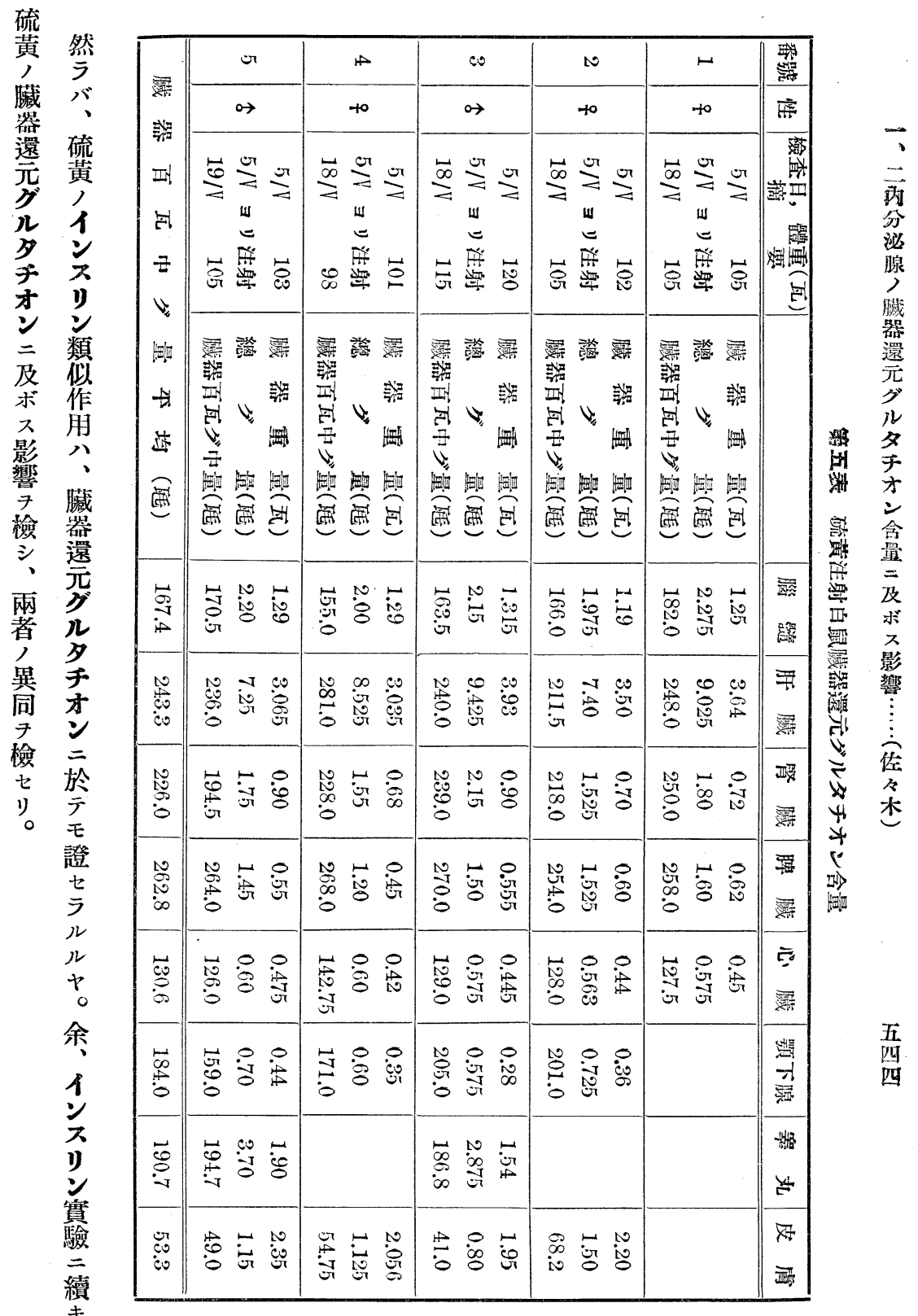



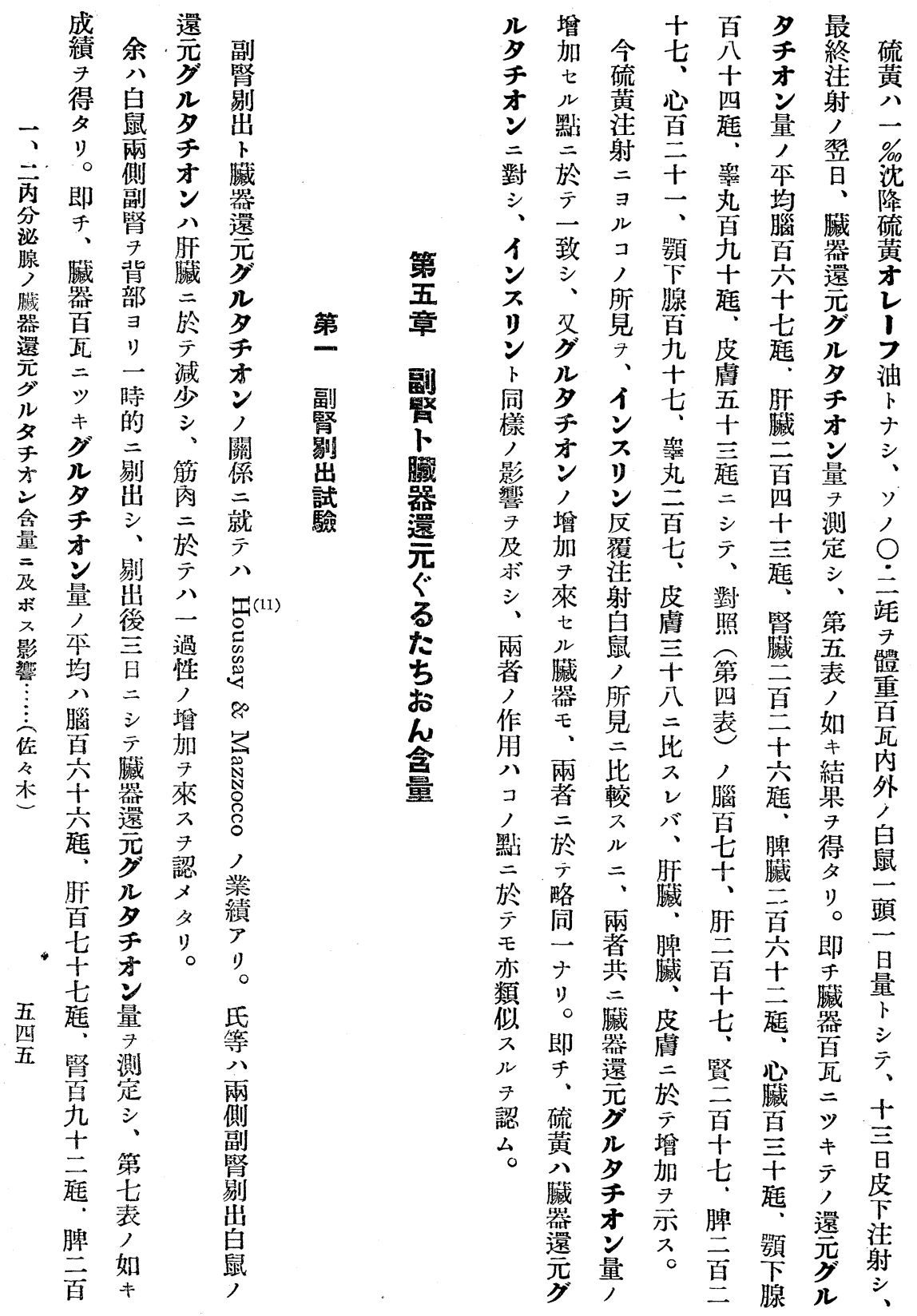


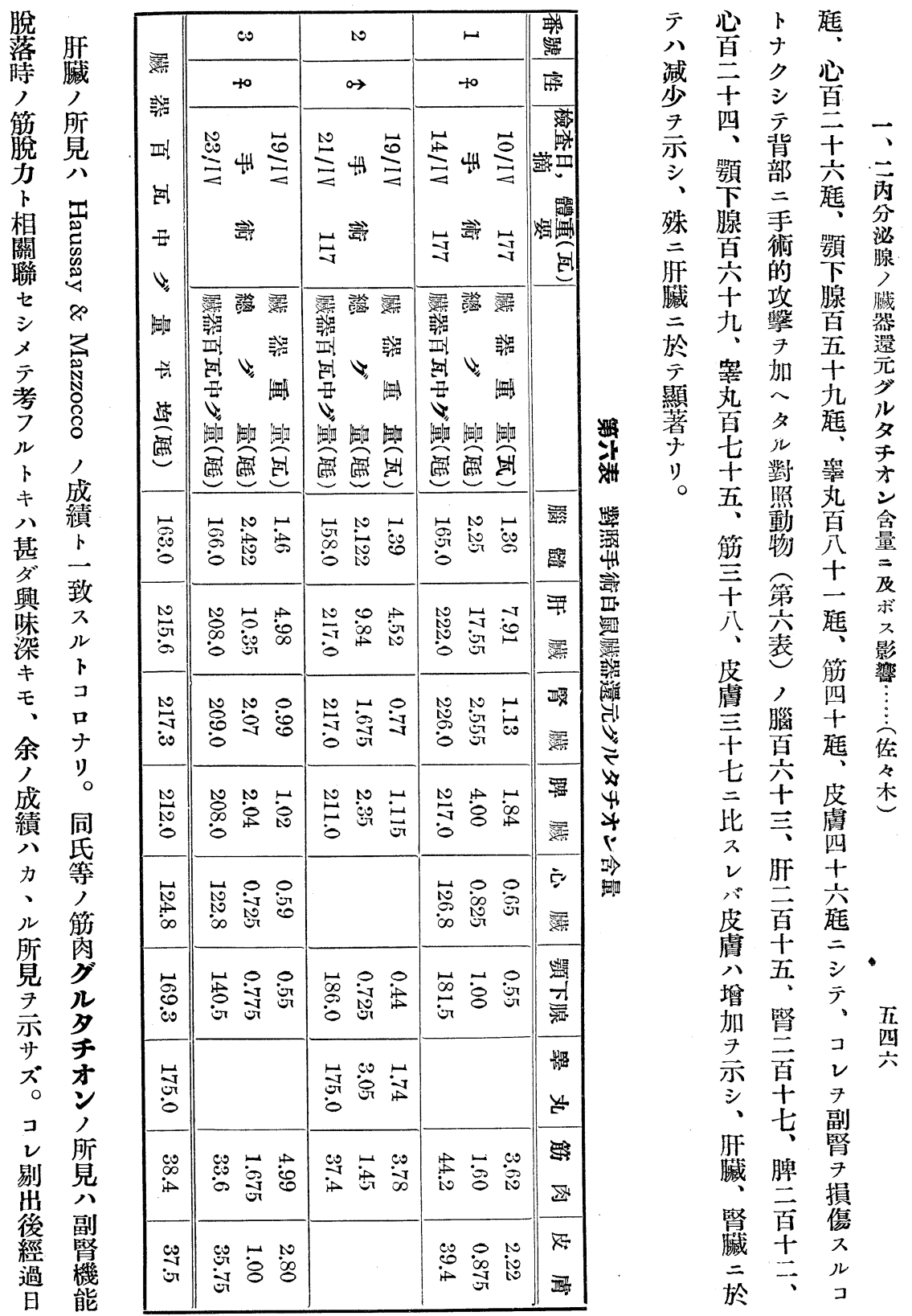




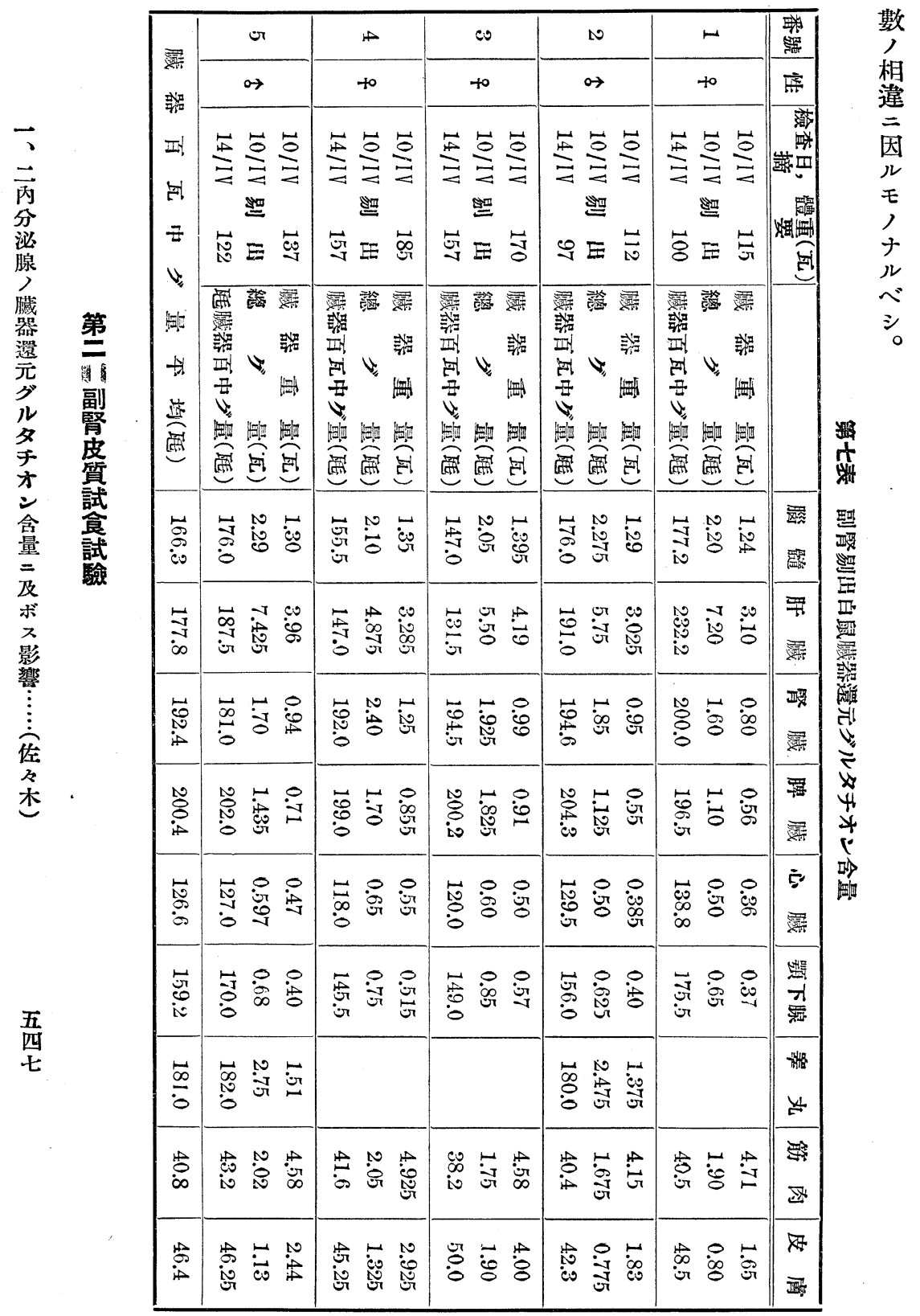




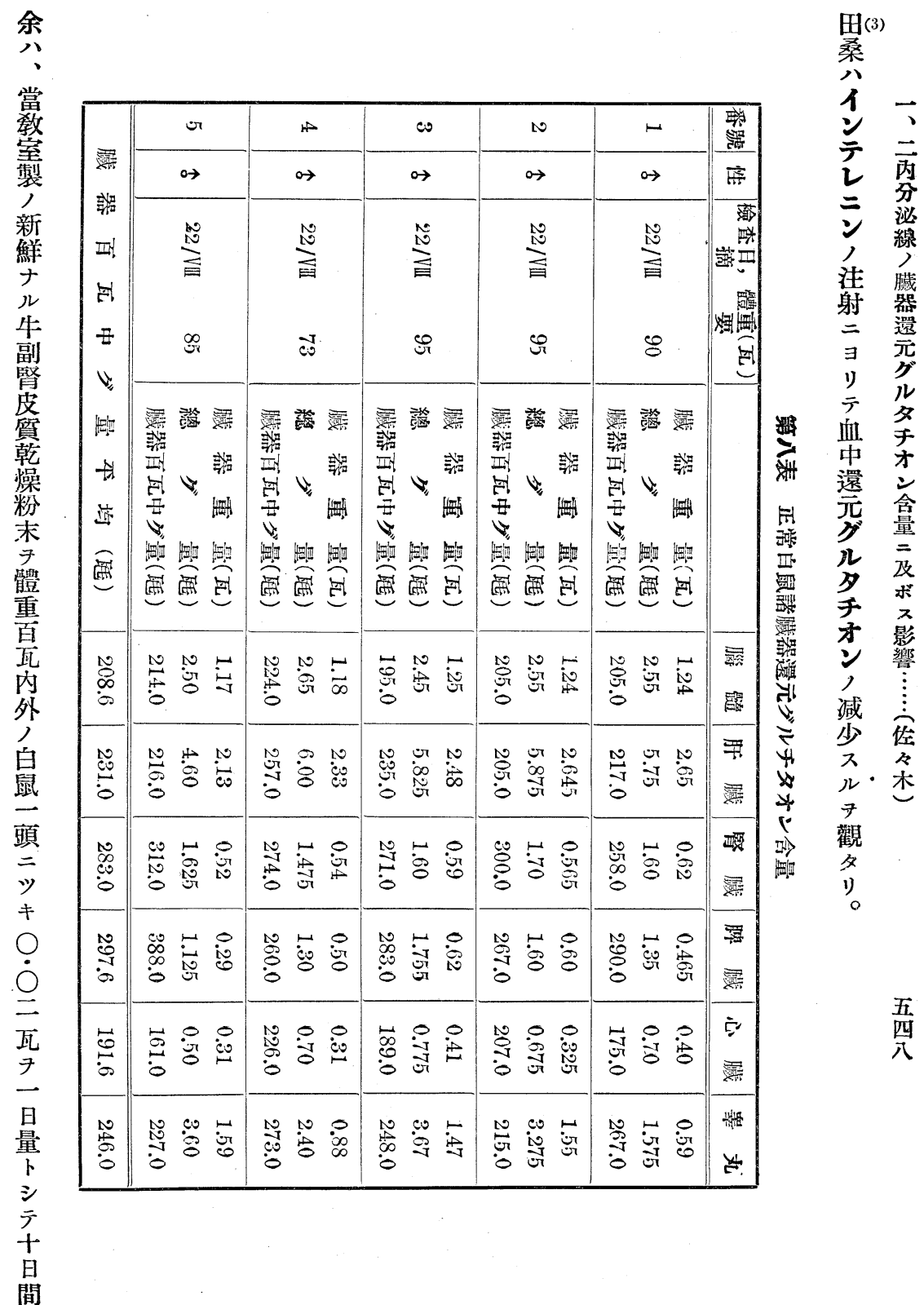




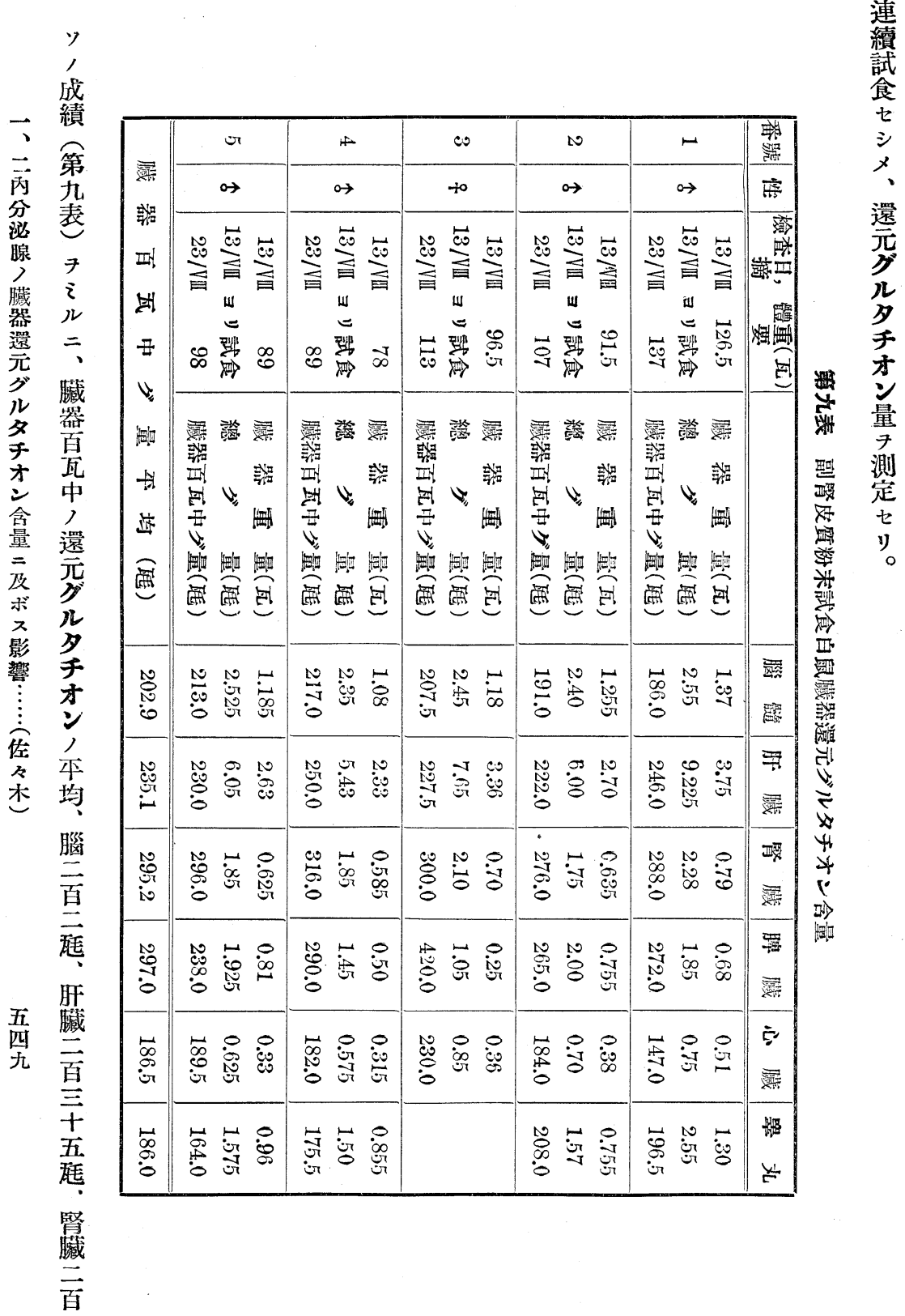




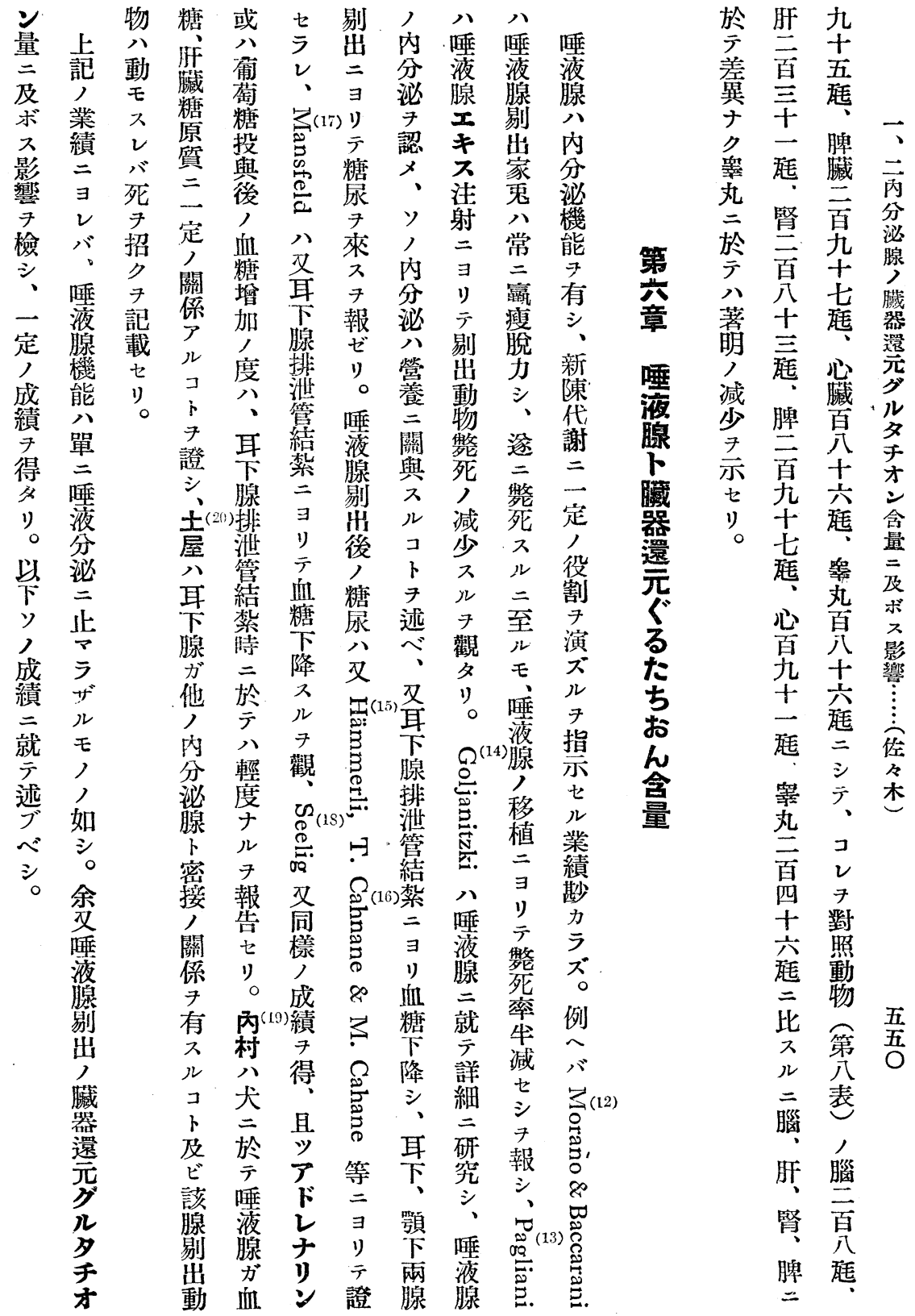




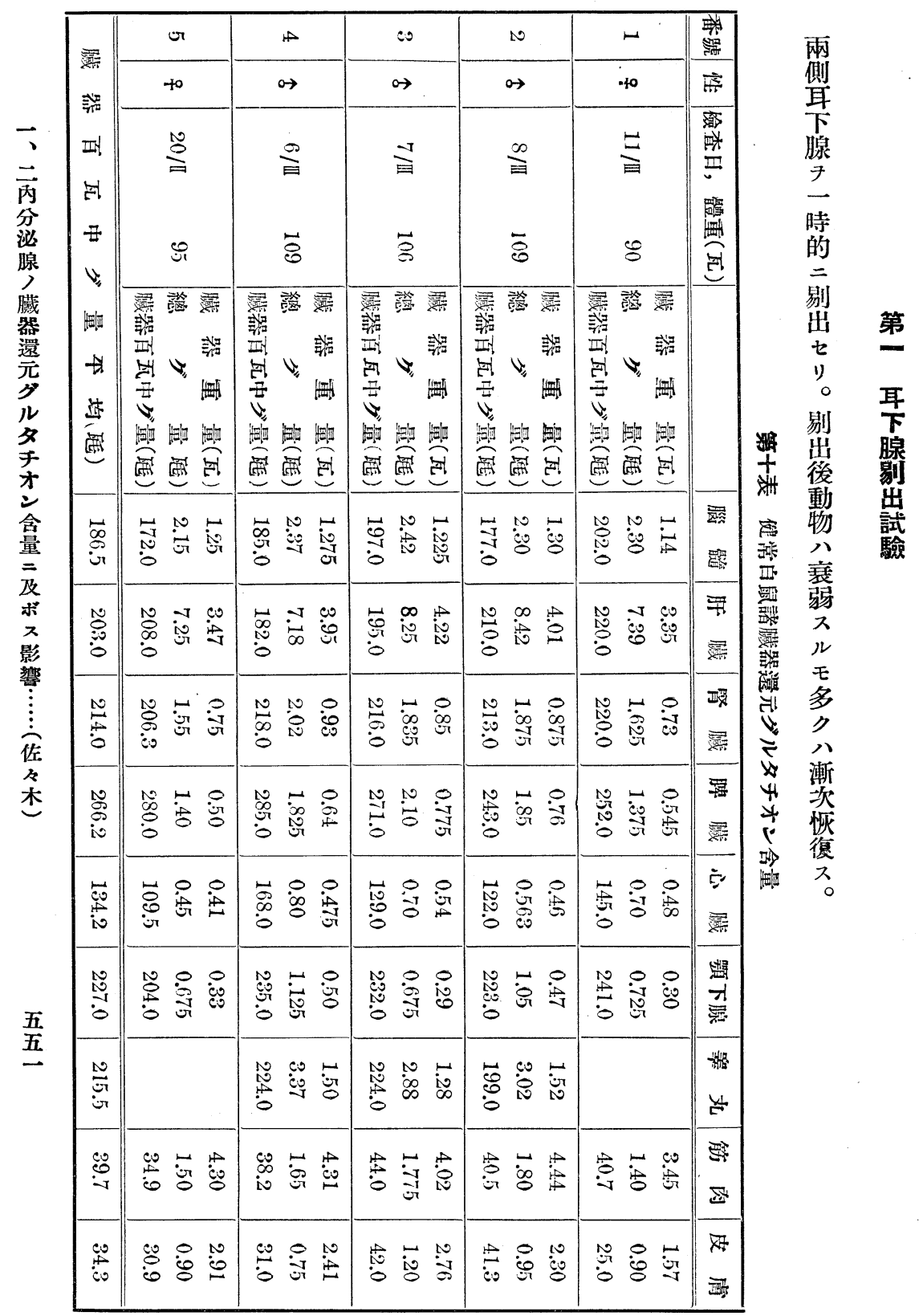




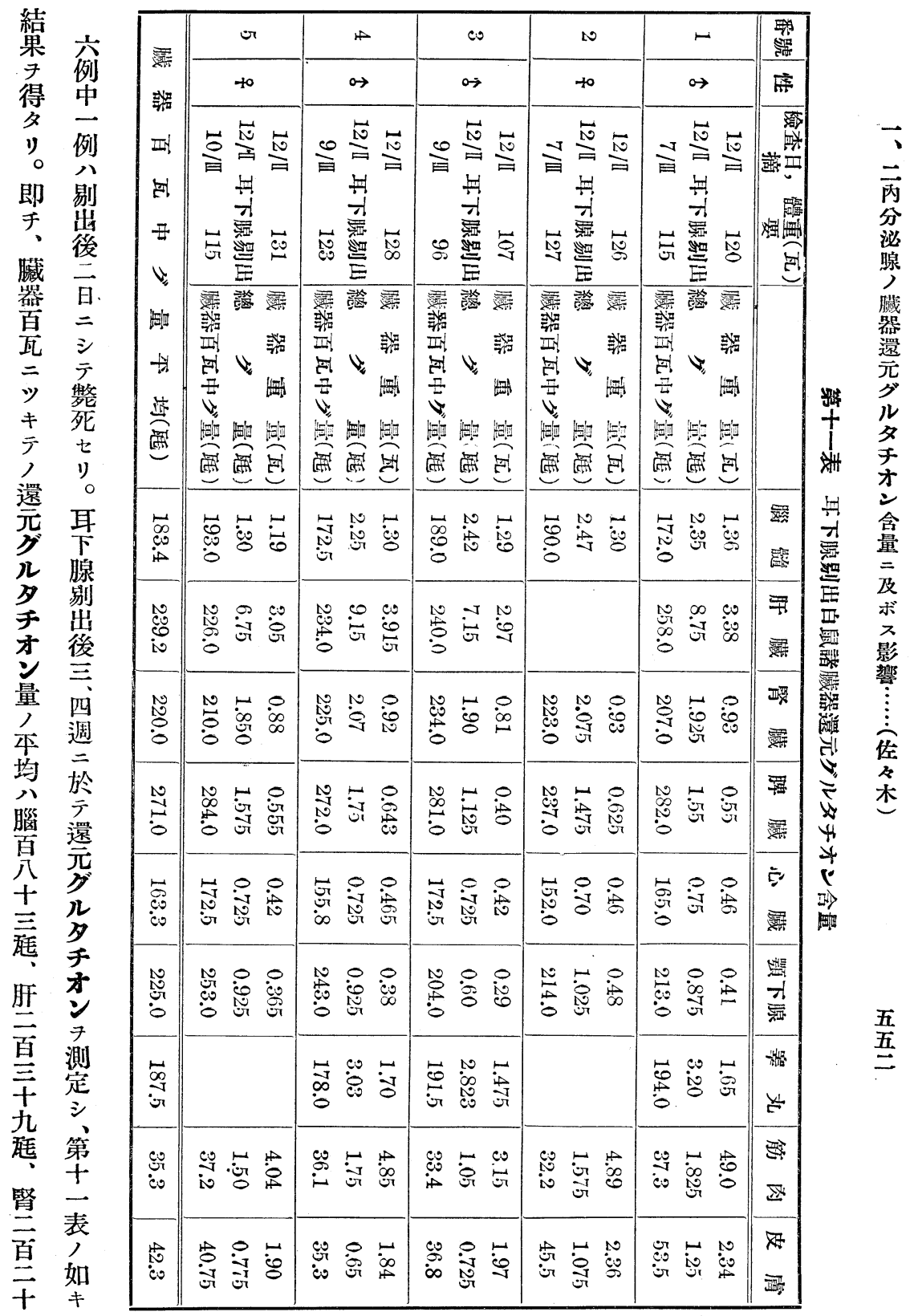




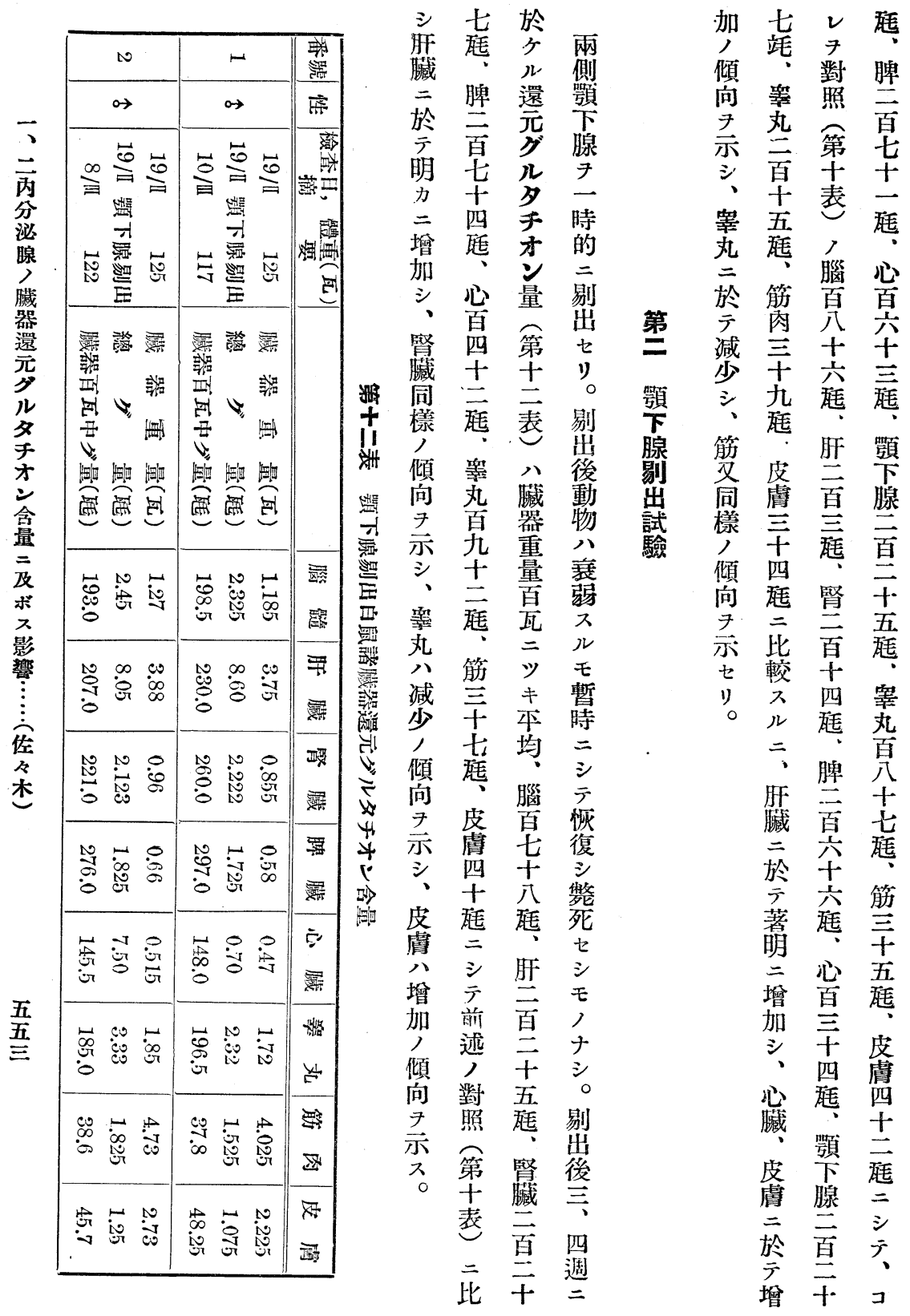




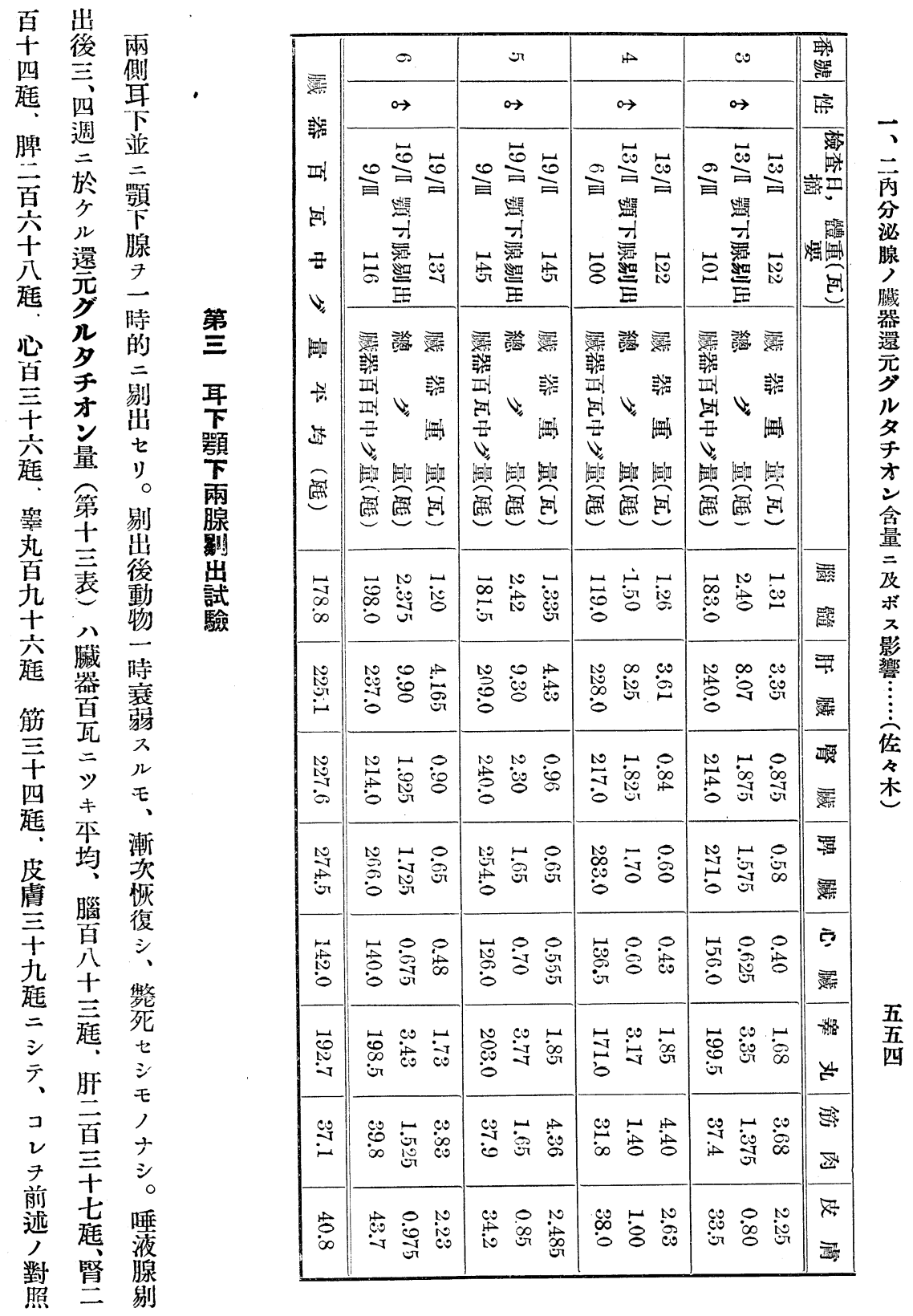




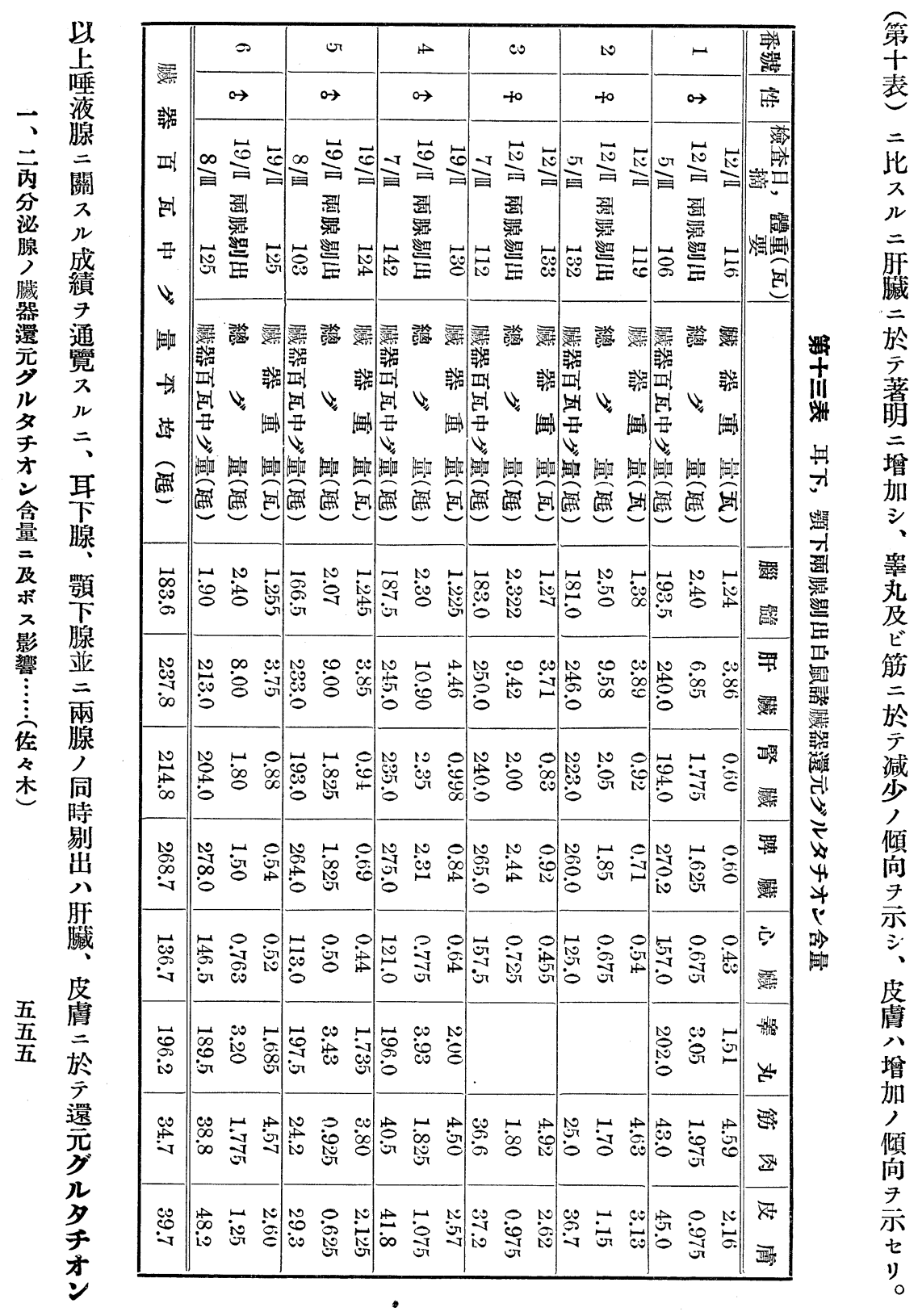




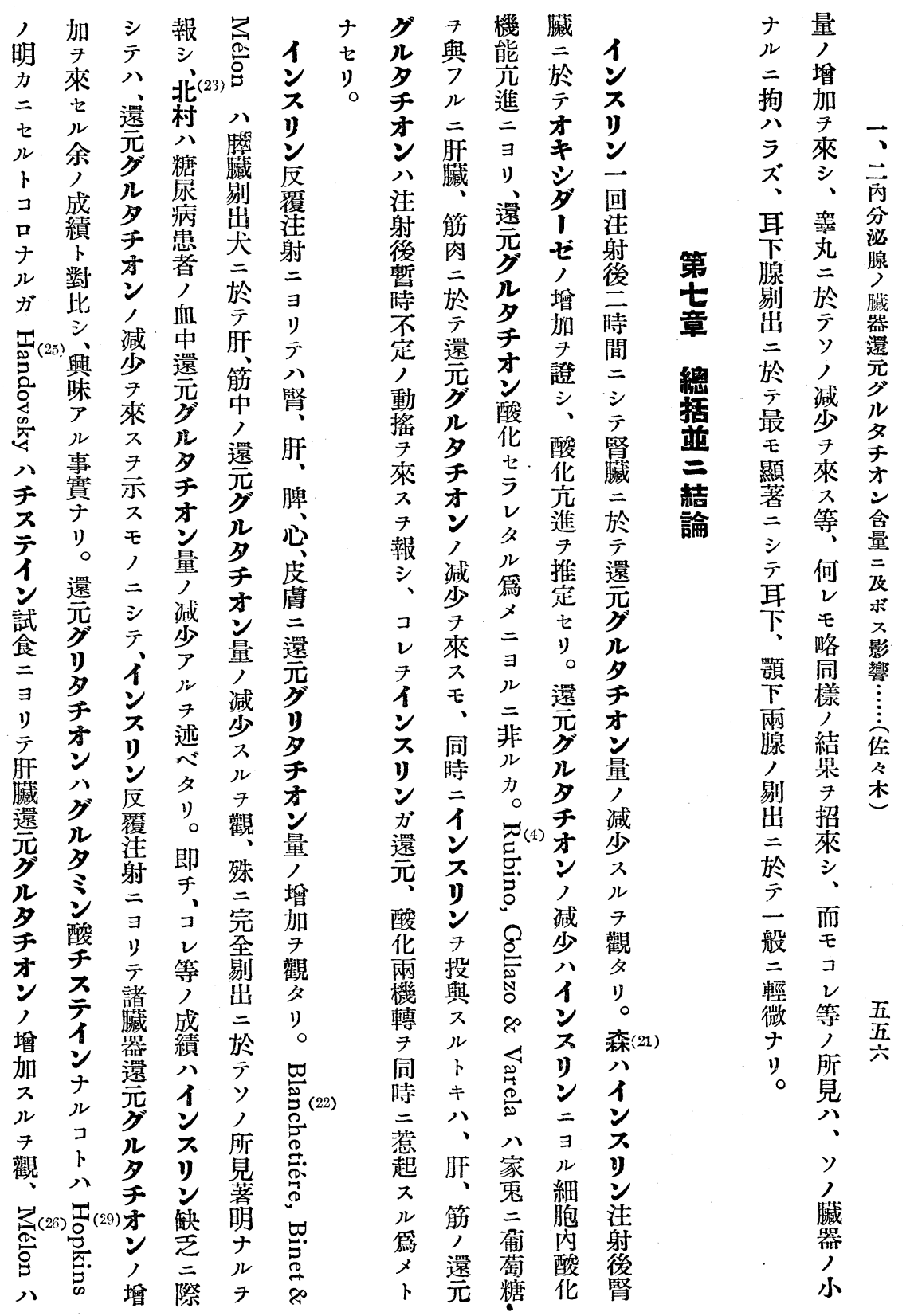




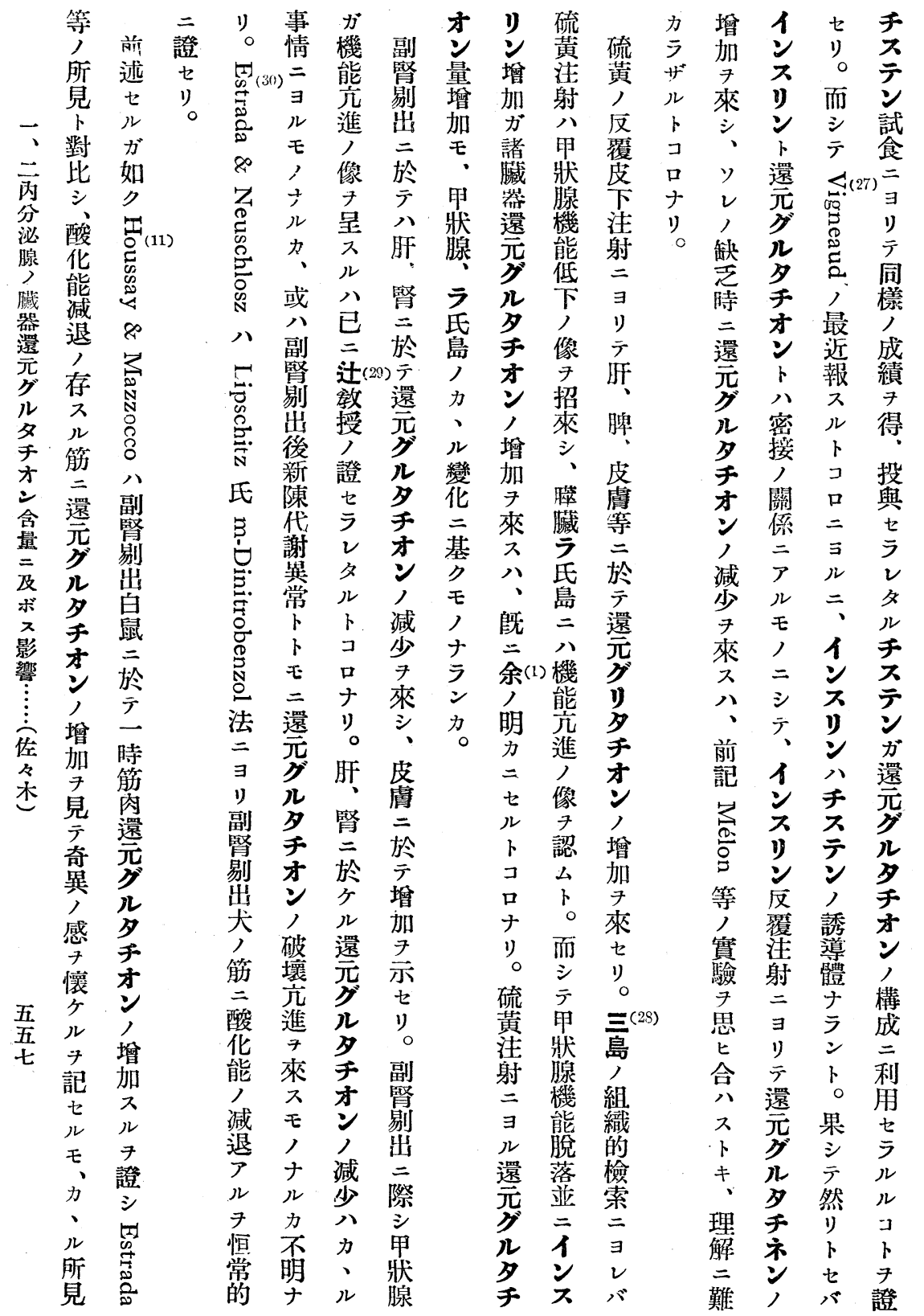




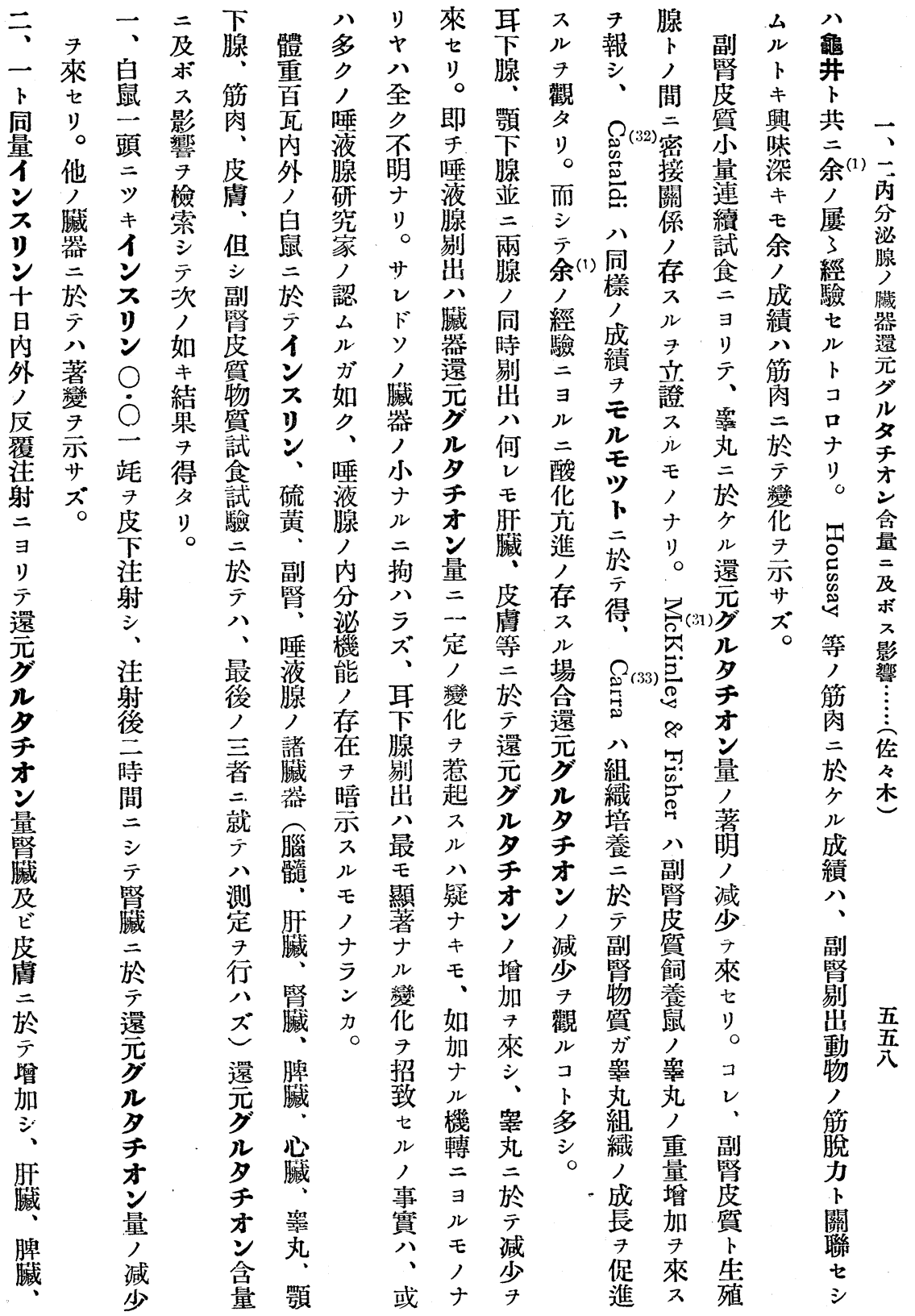




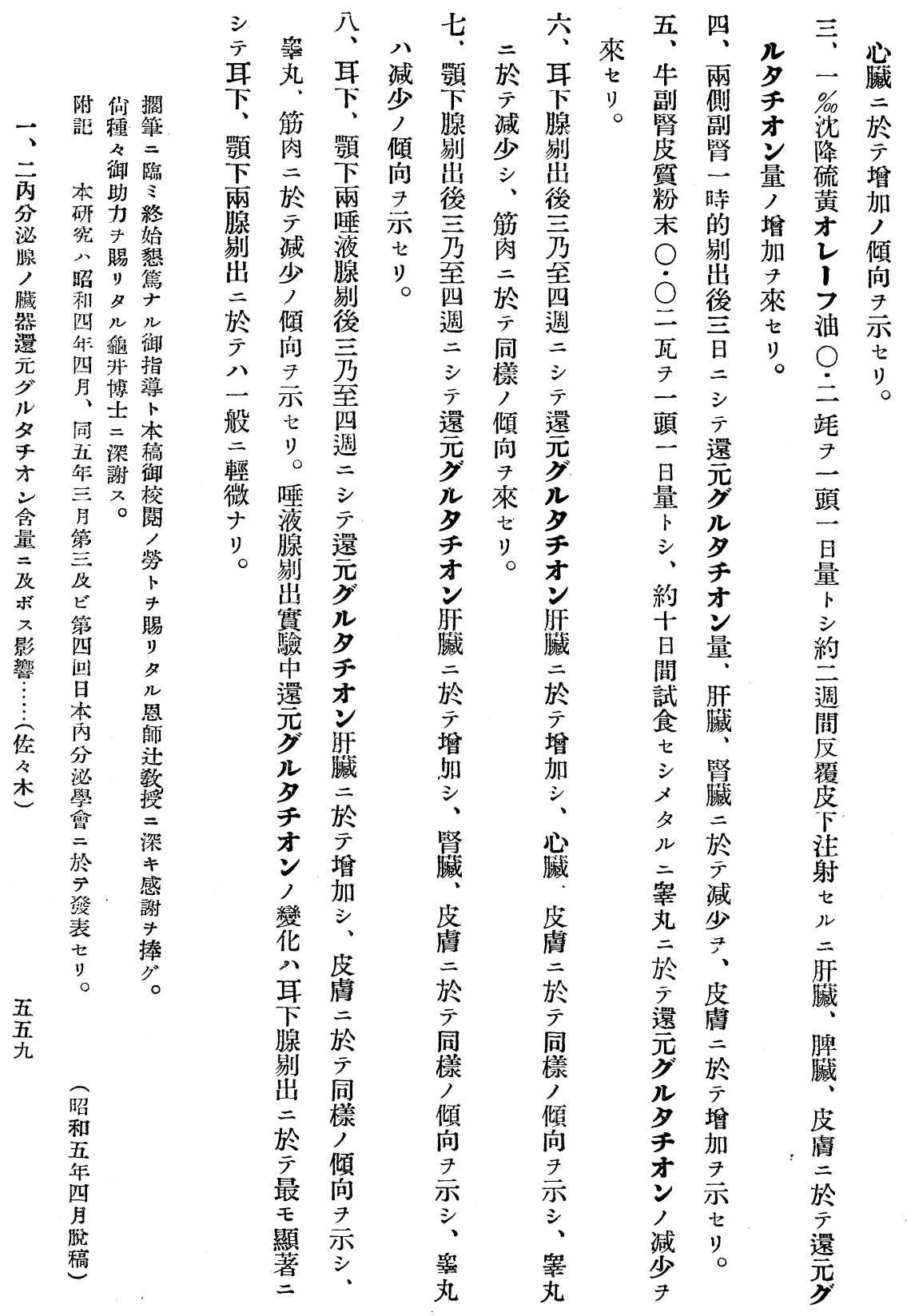




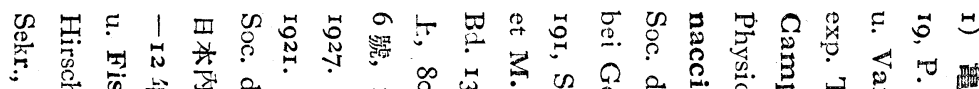

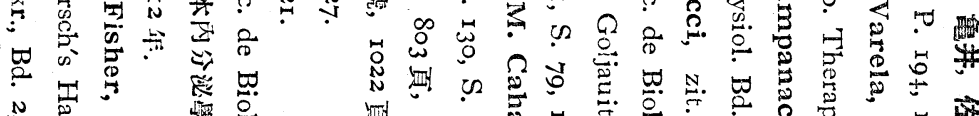

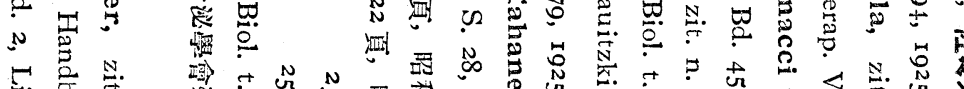

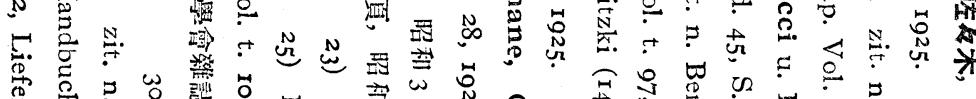

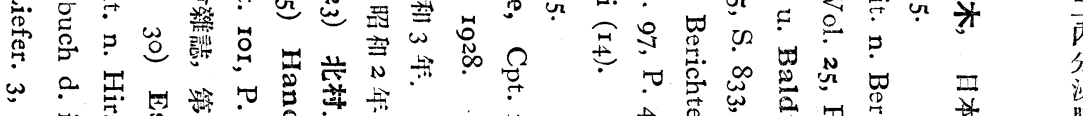

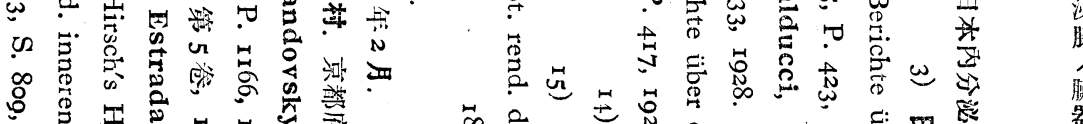

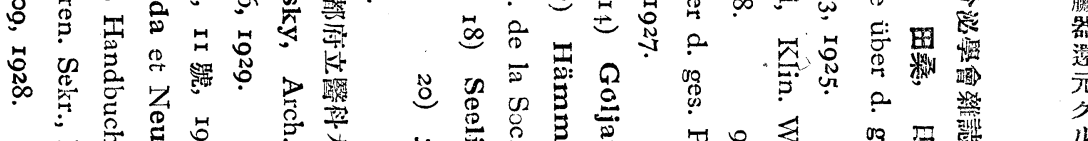

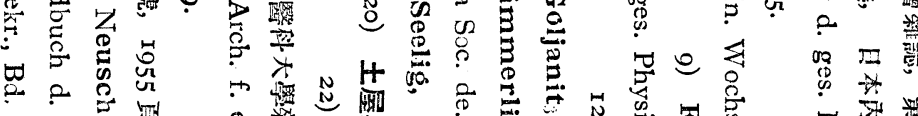

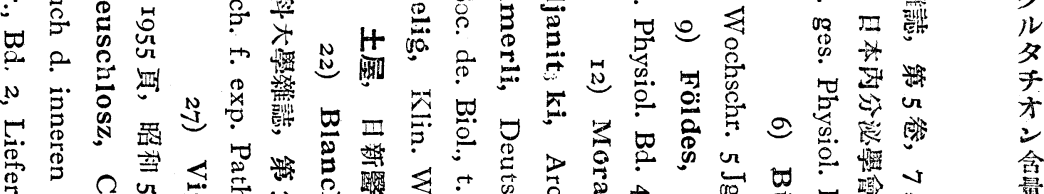

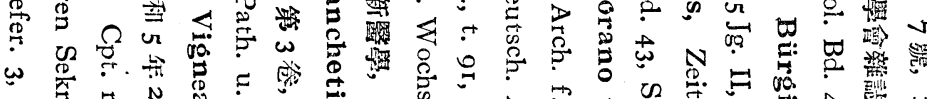

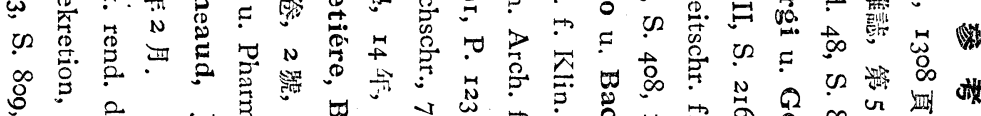

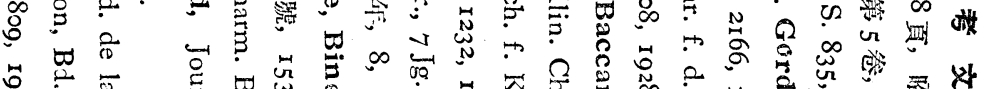

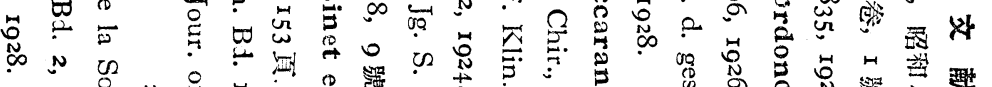

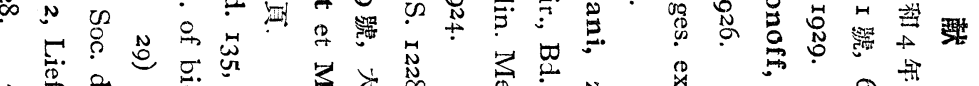

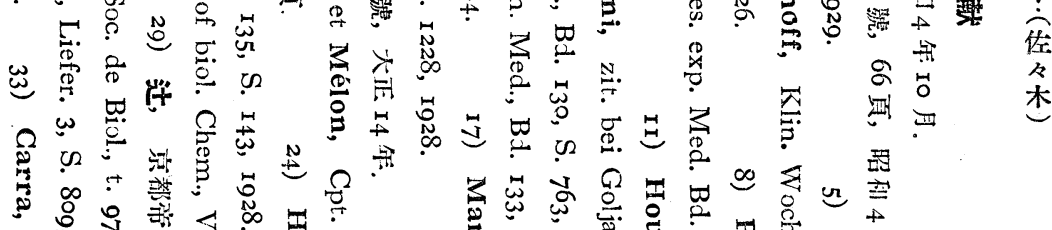

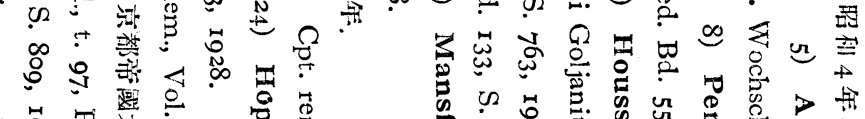

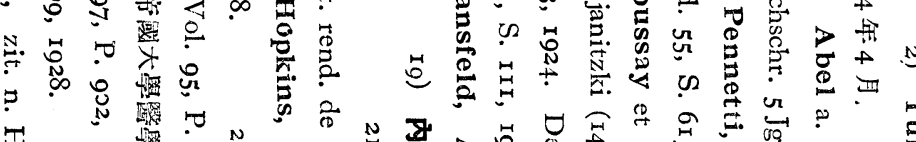

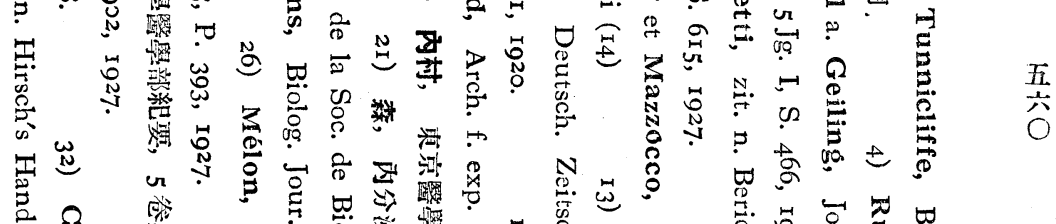

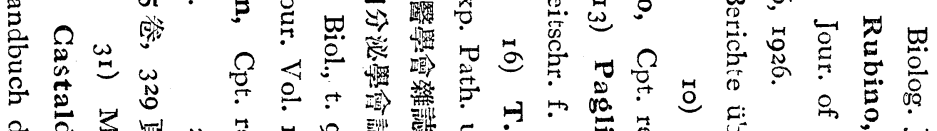

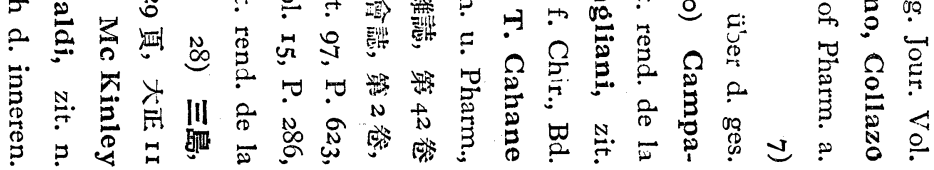


2) Sowohl die subcutane als auch die intraperitoneale Injektion des Insulins ruft Vermehrung des Leberglykogens hervor. Doch ist bei beiden Fällen der Wirkungsgrad derselbe.

3) Der Glykogengehalt des Muskels neigt bei disen Versuchen zur Vermehrung.

(Autoreferat)

\title{
Ueber den Einfluss einiger innersekretorischen Organe auf den reduzierten Glutathiongehalt der verschiedenen Organe.
}

\author{
Von \\ Dr. T. Sasaki
}

(Aus der I med. Klinik der Kaiserl. Univers. zu Kioto in Japan.

Direktor : Prof. Dr. K. Tsuji. )

Anschliessend an eine frühere Arbeit über die Inkretorgane und Glutathion, die der Verfasser mit seinem Kollegen Dr. Kamei in dieser Zeitschrift schon mitgeteilt hat (Bd. V, Heft 7), hat der Verfasser die Untersuchung auf die übrigen Inkretorgane ausgedehnt. Die Untersuchung wurde an weissen Ratten angestellt und der Glutathiongehalt der Organe (Gehirn, Leber, Niere, Milz, Herz, Hoden, Submaxillardrüse, Muskel und Haut, von welchen Organen die drei letzteren beim Versuch mit Nebennierenrindeneinverleibung ausgeschlossen waren) nach Tunnicliffe (Stärkeindikator) bestimmt.

Die Resultate sind die folgenden;-

I) 2 Stunden nach der Insulininjektion (Toronto: O.o I ccm subcutan) nimmt der Glutathiongehalt der Niere ab. Der Glutathiongehalt der übrigen Organe zeigt, verglichen mit der Kontrolle, keinen Unterschied.

2) Bei der wiederholten Insulininjektion (die gleiche Menge wie oben, einmal täglich ca. Io Tage lang) zeigt der Glutathiongehalt in Niere und Haut die Vermehrung, in Leber, Milz und 
Herz Neigung dazu.

3) 3 Tage nach der einzeitigen totalen Nebennierenexstirpation kommt es beim Glutathiongeahlt in Leber und Niere zur Verminderung, dagegen in der Haut zur Vermehrung.

4) Die Fütterung mit Nebennierenrindenpulver ( $0.02 \mathrm{~g}$ pro die und Kopf, ca. IO Tage lang) führt zur Glutathionverminderung in den Hoden, ab er $z \mathrm{u}$ keiner Veränderung in den übrigen Organen.

5) 3-4 Wochen nach der Parotisexstirpation zeigt der Glutathiongehalt in der Leber Vermehrung, in Herz und Haut geringe Neigung dazu, dagegen Verminderung in den Hoden und die gleiche Neigung dazu im Muskel.

6) 3-4 Wochen nach der Submaxillardrüsenexstirpation zeigt der Glutathiongehalt in der Leber Vermehrung, in Niere und Haut Neigung dazu, dagegen im Hoden Neigung zur Verminderung.

7) Gleichzeitige Parotis- und Submaxillarexstirpation bewirkt nach $3-4$ Wochen Glutathionvermehrung in der Leber und Neigung dazu in der Haut, dagegen Neigung zur Verminderung in Hoden und Muskel.

Von den obigen drei Speicheldrüsenversuchen ist die Veränderung des Glutathiongehalts bei der Parotisexstirpation am auffallendsten.

Von mehreren Forschern ist berichtet worden, dass Schwefel die gleiche Wirkung wie Insulin habe. Der Verfasser untersuchte die Wirkung des Schwefels auf den Glutathiongehalt der Organe und erhielt die folgenden Ergebnisse.

Die wiederholte subkutane Schwefelinjektion ( 0.2 ccm des I \% igen Schwefelolivenöls pro die und Kopf ca. 2 Wochen lang) führt zur Vermehrung des Glutathiongehalts in Leber, Milz und Haut, welche Resultate denen bei der wiederholten Insulininjektion sehr ähnlich sind. (Autoref erat) 